\title{
Convective Heat Transfer In Airflow Through A Duct With Wall Thermal Radiation
}

\author{
T. T. Chandratilleke ${ }^{1}$, R. Narayanaswamy and P. Wangdhamkoom \\ Department of Mechanical Engineering, Curtin University of Technology \\ GPO Box U 1987, Perth, Western Australia 6845 \\ E-mail: t.chandratilleke@ curtin.edu.au
}

\begin{abstract}
This paper presents a numerical investigation on airflow through a heated horizontal rectangular duct wherein the model considers the combined modes of natural and forced convection heat transfer and the thermal radiation from duct walls. The duct periphery is differentially heated with known temperature profiles imposed on the two opposite vertical sidewalls while the other two walls are treated as adiabatic. The air enters into the duct hydrodynamically fully developed and flows steadily under laminar conditions undergoing thermal development within the duct. Considering several temperature profiles on the two vertical sidewalls, the numerical simulation generates the heat transfer rates and associated fluid flow patterns in the duct for a range of airflow rates, duct aspect ratios and surface emissivity. The variation of local Nusselt number at duct walls and the fluid flow patterns are critically examined to identify thermal instabilities and the significance of wall thermal radiation effects on the overall heat transfer rates.
\end{abstract}

\section{Introduction}

Clear understanding of heat and fluid flow characteristics in heated ducts is essential for developing reliable design tools for a wide range of thermal energy conversion devices such as compact heat exchangers, electronic circuitry cooling systems and gas turbine blade cooling. Whilst the heat flow processes within ducts are fundamentally based on the combined mechanics of convection and thermal radiation, most research work on heated ducts ignores these multimode heat transfer behaviour to simplify complexities of analytical models. They often overlook the relevance of natural convection in flow through heated ducts and predominantly focus on forced convection mechanism with no account for wall thermal radiation. This reflects a major deficiency in the current state of the thermal design technology for heated ducts.

In heated ducts, the external heating induces a lateral fluid movement called secondary flow, which is essentially the buoyancy-driven natural convection current superimposed on the main axial flow. The orientation of wall heating is a primary factor affecting the characteristics of secondary flow. In view of this, the early studies have examined fluid flows in rectangular ducts heated only at the bottom wall. The experimental work on laminar airflow in a bottom-heated duct by Incropera and Maughan $[1,2]$ showed a special flow condition called thermal instability, which is indicated by fluctuating Nusselt number. In a similar study by Nyce et al.[3], the secondary fluid movement was found to be independent of flow Reynolds number and the thermal instability was observed even at a low Reynolds number of 18.75. For a duct cooled at the top wall, Huang and Lin [4] observed a flow

1 T. T. Chandratilleke 
transition from steady laminar longitudinal vortex flow to unsteady chaotic flow, which did not occur in ducts heated from the bottom.

The literature reports only a limited number of studies with sidewall heating. Silekens et al.[5] examined rectangular ducts with symmetrical heating at the two opposite sidewalls and have illustrated that the thermally induced secondary flow would substantial increase heat transfer. Examining mixed convection in a rectangular duct heated from one side wall, Gau et al.[6] concluded that fluid stratification in the upper duct section would reduce the overall heat transfer rate to the fluid. A study by Corcione [7] has shown that the bottom wall heat transfer rates could be improved if the side vertical walls were cooled (or heated) instead of insulating them.

The published literature reports only a very few studies on heated ducts incorporating mixed mode analysis of convective heat transfer mechanisms and surface thermal radiation. This is because analytical models could be highly simplified by assuming negligible interaction between thermal radiation and convection in flow through ducts. While significance of radiation is customarily associated with high temperature situations, recent evidence strongly suggests that even at moderate surface temperatures, thermal radiation not only substantially contributes towards the mixed mode heat transfer, but also enhances natural convection process to promote overall heat dissipation rates in heated ducts $[15,16,17,18]$. One such limited study by Yang and Ebadian[8] concludes that the duct wall emissivity significantly influences the combined heat transfer rates wherein the total Nusselt number increases with higher surface radiation effects.

In a differentially heated duct, the thermal radiation from externally heated walls would alter the equilibrium surface temperature of unheated walls. This in turn will change not only the intensity of thermally induced convection currents, but also the overall heat dissipation from (heated and unheated) duct walls to the fluid. Thus, a careful examination of both radiative and convective heat transfer processes is necessary for a more realistic description of heat transfer characteristics in differentially heated ducts. The present numerical study performs a parametric investigation on the airflow through a horizontal duct with specified wall heating configurations to ascertain the significance of mixed convection and surface radiation towards the overall heat transfer rates.

\section{Nomenclature}

$\begin{array}{lll}\mathrm{A} & {\left[\mathrm{m}^{2}\right]} & \text { Duct cross sectional area } \\ \mathrm{AR} & {[-]} & \text { Duct aspect ratio W/H } \\ \mathrm{D}_{\mathrm{h}} & {[\mathrm{m}]} & \text { Hydraulic diameter } 2 \mathrm{WH} /(\mathrm{W}+\mathrm{H}) \\ \mathrm{g} & {\left[\mathrm{m} / \mathrm{s}^{2}\right]} & \text { Gravitational acceleration } \\ \mathrm{Gr} & {[-]} & \text { Grashof number } \mathrm{Gr}=\mathrm{g}\left(\mathrm{T}_{\mathrm{h}}-\mathrm{T}_{\mathrm{c}}\right) \mathrm{H}^{3} / \mathrm{g}^{2} \\ \mathrm{Gr} * & {[-]} & \text { Modified Grashof number } \mathrm{Gr}=\mathrm{g} \quad \mathrm{q}^{\prime \prime} \mathrm{H}^{4} / \mathrm{k}^{2} \\ \mathrm{~h} & {\left[\mathrm{~W} / \mathrm{m}^{2} \cdot \mathrm{K}\right]} & \text { Heat transfer coefficient } \\ \mathrm{H} & {[\mathrm{m}]} & \text { Duct height } \\ \mathrm{k} & {[\mathrm{W} / \mathrm{m} \cdot \mathrm{K}]} & \text { Thermal conductivity } \\ \mathrm{L} & {[\mathrm{m}]} & \text { Duct length } \\ \mathrm{Nu} & {[-]} & \text { Nusselt number Nu=h } \mathrm{D}_{\mathrm{h}} / \mathrm{k} \\ \mathrm{Pr} & {[-]} & \text { Prandtl number } \\ \mathrm{Pl} & {[-]} & \text { Planck number } \\ \mathrm{q} & {\left[\mathrm{W} / \mathrm{m}^{2}\right]} & \text { Heat flux - convective or radiative } \\ \mathrm{Ra} & {[-]} & \text { Rayleigh number GrPr } \\ \mathrm{Re} & {[-]} & \text { Reynolds number } \mathrm{U}_{\mathrm{in}} \mathrm{D}_{\mathrm{h}} / \\ \mathrm{T} & {[\mathrm{K}]} & \text { Temperature } \\ \mathrm{T} * & {[-]} & \text { Dimensionless temperature }\left(\mathrm{T}-\mathrm{T}_{\mathrm{c}}\right) /\left(\mathrm{T}_{\mathrm{h}}-\mathrm{T}_{\mathrm{c}}\right) \\ \mathrm{U} & {[\mathrm{m} / \mathrm{s}]} & \text { Average fluid velocity } \\ \mathrm{u} & {[\mathrm{m} / \mathrm{s}]} & \text { Fluid velocity } \\ \mathrm{W} & {[\mathrm{m}]} & \text { Duct width } \\ \mathrm{x} & {[\mathrm{m}]} & \text { x-coordinate } \\ \mathrm{y} & {[\mathrm{m}]} & \text { y-coordinate } \\ \mathrm{Z} & {[-]} & \text { Dimensionless z-coordinate }\end{array}$




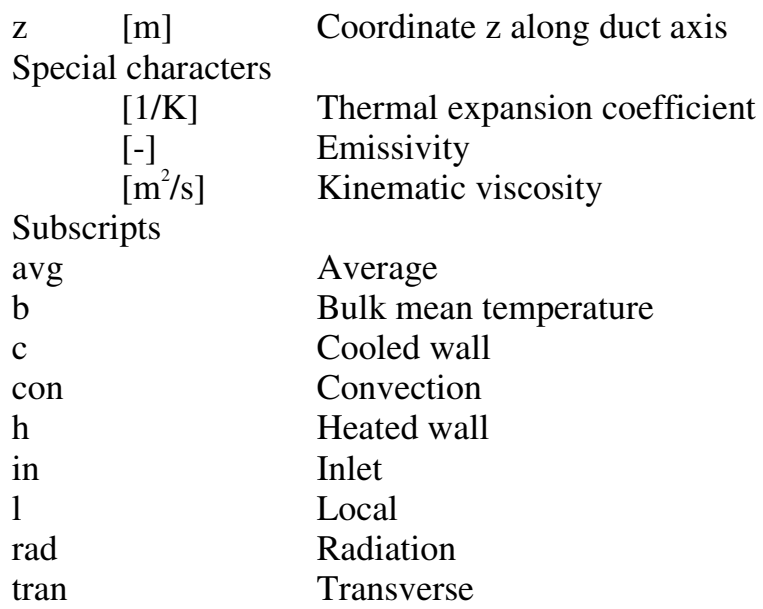

\section{Numerical model and solution}

The geometrical model of the analysis is illustrated in Figure 1 and consists of a horizontal rectangular duct whose aspect ratio $\mathrm{W} / \mathrm{H}$ is chosen to be $0.5,1$, and 2 . A sufficient duct length is considered to ensure thermally fully developed conditions at the duct outlet. The duct circumference is differentially heated where known temperature profiles are applied to the two vertical walls while the two horizontal walls are assumed to be adiabatic. Three wall heating configurations used in the analysis are illustrated in Figure 2. In these, the cold wall is kept at a constant temperature of $300 \mathrm{~K}$ while a maximum temperature of $350 \mathrm{~K}$ is considered for the hot wall. The airflow through the duct is taken to be laminar and hydrodynamically fully developed. The physical properties of air are assumed to vary linearly with temperature and are evaluated for conditions at duct inlet [10].

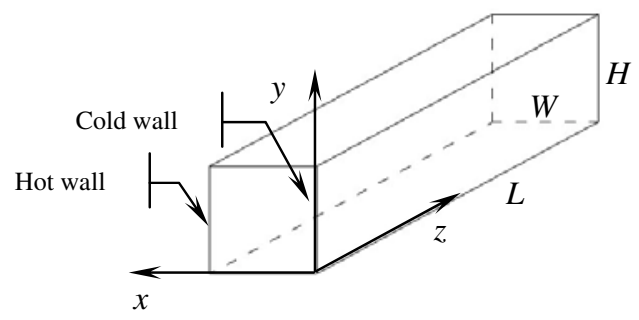

Figure 1. Geometrical model of duct

Based on the geometrical model, the solution domain with a grid structure is prepared and solved using the computational fluid dynamics solver FLUENT [14]. The Body Force Weight scheme is used for pressure discretisation to capture the effects of natural convection. It is assumed that, the walls are diffuse reflectors and emitters, while the working fluid is a radiatively non-participating medium. The Discrete Ordinates Method (DOM) is chosen to model the surface radiation heat transfer among internal duct walls, as it provides a better compatibility with the finite volume method used for the analysis. The SIMPLE algorithm is applied to the pressure-velocity coupling. Momentum and energy equations are discretised under the second order upwind scheme.

The operating parameters for the present study are selected to obtain Grashof number in the range of $2 \times 10^{3} \cdot \mathrm{Gr} \bullet 1 \times 10^{6}$ at a fixed Reynolds number of 100 . Two emissivity values of 0.05 and 0.85 are considered for the simulation to obtain extreme conditions for surface thermal radiation. 


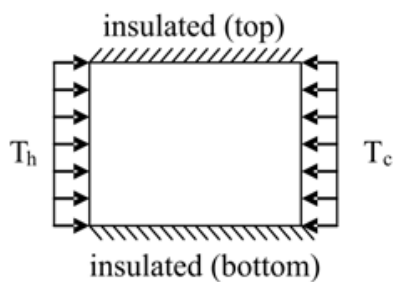

(a) Case 1

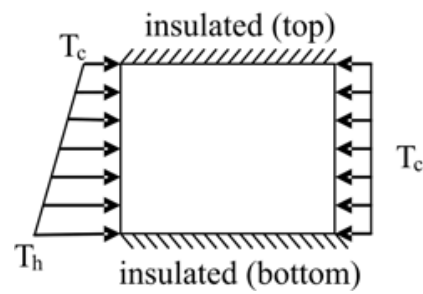

(b) Case 2

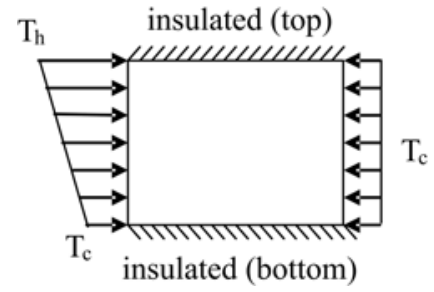

(c) Case 3

Figure 2. Duct wall heating configurations

The numerical solution is assumed to have converged when the net residual of the total heat transfer rates for successive iteration cycles is less than one percent. This convergence criterion ensured that the scaled residuals of mass and momentum fluxes were also less than $10^{-4}$ and $10^{-5}$, respectively. The grid sensitivity analysis was also performed for a range of grid sizes. A grid of 50x50x400 provided less than 0.2 percent deviation in Nusselt number and was chosen as the suitable grid size for the simulation.

From the converged solution, the individual heat transfer rates due to mixed convection and surface thermal radiation are separately evaluated. Using these values, the convective Nusselt number $\mathrm{Nu}_{\text {con }}$ and the radiative Nusselt number $\mathrm{Nu}_{\mathrm{rad}}$ are computed from the definition of the local Nusselt number,

$$
\mathrm{Nu}_{1}=\frac{\mathrm{q}^{\prime \prime} \mathrm{D}_{\mathrm{h}}}{\mathrm{k}\left(\mathrm{T}_{\mathrm{w}}-\mathrm{T}_{\mathrm{b}}\right)}
$$

where $\mathrm{q}$ " is the convective or radiative heat flux depending on the quantity to be evaluated. In Equation (1), the bulk mean fluid temperature $\mathrm{T}_{\mathrm{b}}$ at duct cross section is given by,

$$
\mathrm{T}_{\mathrm{b}}(\mathrm{z})=\frac{1}{\mathrm{U}(\mathrm{z}) \mathrm{A}} \int \mathrm{u}(\mathrm{x}, \mathrm{y}, \mathrm{z}) \mathrm{T}(\mathrm{x}, \mathrm{y}, \mathrm{z}) \mathrm{dA}
$$

where $\mathrm{U}(\mathrm{z})$ is the average fluid velocity for each cross section. The average $\mathrm{Nu}$ for each cross section (transverse average) along the heated wall is then evaluated from,

$$
\mathrm{Nu}_{\text {tran }, \mathrm{avg}, \mathrm{h}}=\frac{\sum_{\mathrm{Y}=0}^{\mathrm{Y}=1} \mathrm{Nu}_{1}}{\mathrm{~N}}
$$

where $N$ is the number of $N u_{l}$ nodal values on the heated wall. The total Nusselt number $\mathrm{Nu}_{\text {total }}$ is computed from,

$$
\mathrm{Nu}_{\text {total }}=\mathrm{Nu}_{\text {con }}+\mathrm{Nu}_{\text {rad }}
$$

\section{Results and Discussion}

\subsection{Mixed forced and natural convection effects}

For all duct aspect ratios, the transverse average convective Nusselt number at any duct cross section rapidly increases with Grashof number, as typically illustrated in Figure 3 for Case (1) wall heating configuration. This clearly indicates the favourable contribution from natural convection to the overall heat transfer process in heated ducts. 


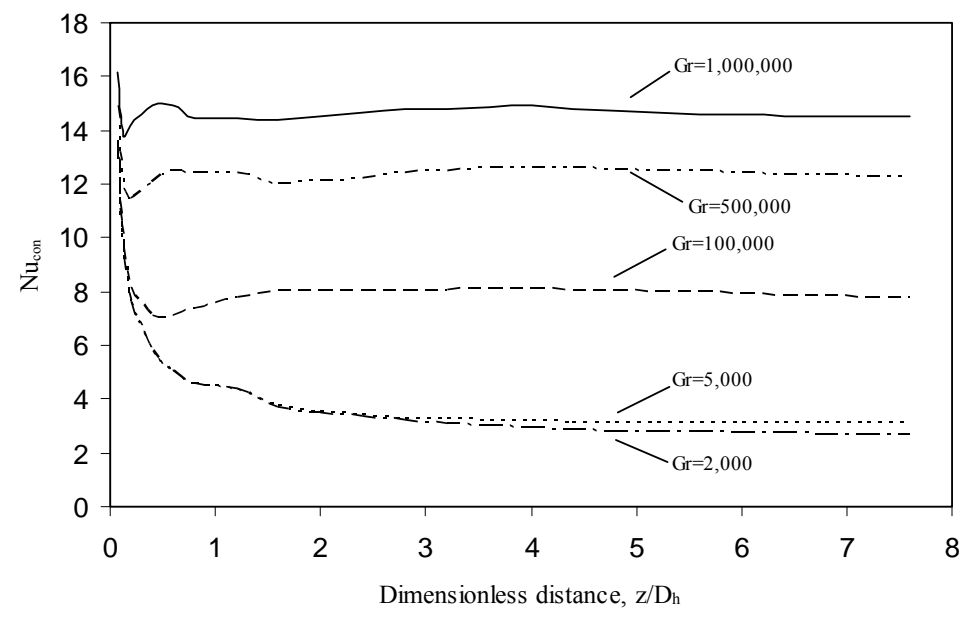

Figure 3. Variation of transverse average convective Nusselt number for $A R=1$ and $=0.05$

When $\mathrm{Gr}$ is low ( $\mathrm{Gr}=2000$ and 5000), the flow is dominated by forced convection. The $\mathrm{Nu}$ follows the conventional behaviour where it steadily declines with the thermally development of the flow due to the growth of thermal boundary layer. This trend changes when Gr is about 100,000 where the natural convection effects are manifested in the flow and mixed convection becomes significant. Then, $\mathrm{Nu}$ shows a marginal reduction at first near duct inlet and reaches a near-constant value over the rest of the duct. For Gr above 100,000, Nu does not show a reduction at duct inlet as for lower $\mathrm{Gr}$ and increases towards a steady value. A physical explanation is given below for the behaviour with $\mathrm{Gr}>100,000$.

For $\mathrm{Gr} \geq 100,000$, the differentially heated sidewalls induce convection currents that are comparable in strength to the axial flow through the duct. This buoyancy-driven secondary fluid circulation interacts and shifts the axial flow towards the hot wall creating steeper velocity gradients there, as illustrated in Figure 4. Consequently, both natural and forced convection mechanisms at the hot wall are enhanced along with overall heat transfer rates to fluid. Similarly, the downward-directed buoyancy promotes the convective heat transfer at the cold wall.

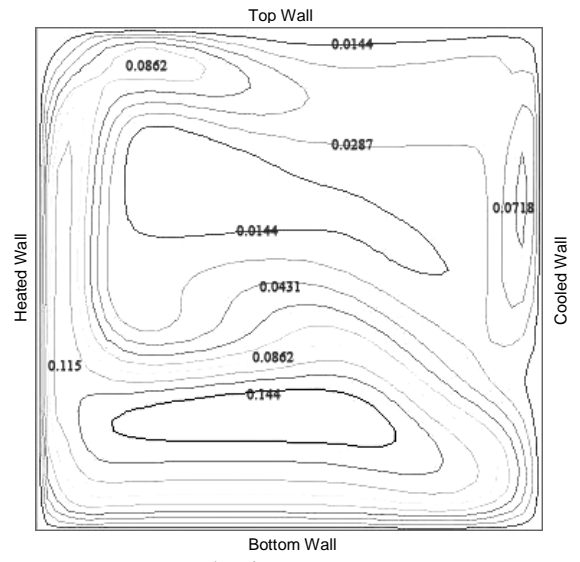

Velocity contours

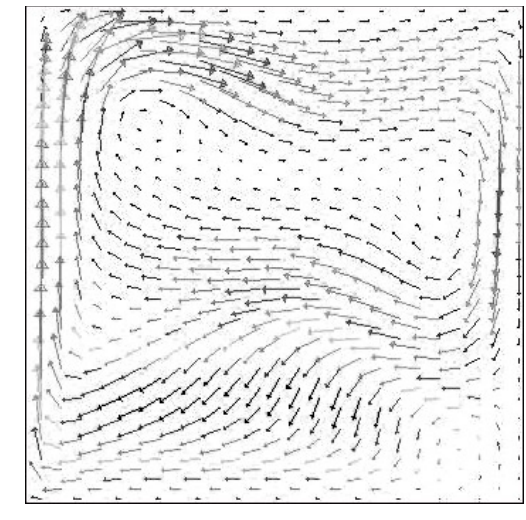

Velocity vectors

$$
\mathrm{AR}=1, \quad=0.05, \mathrm{Gr}=1,000,000
$$

Figure 4. Axial velocity contours and vectors in duct 


\subsection{Effects of Radiation heat transfer}

The most visible effects of thermal radiation are illustrated in Figure 5, which shows the temperature contours of the top and bottom adiabatic duct walls for cases of high and low wall surface emissivity.
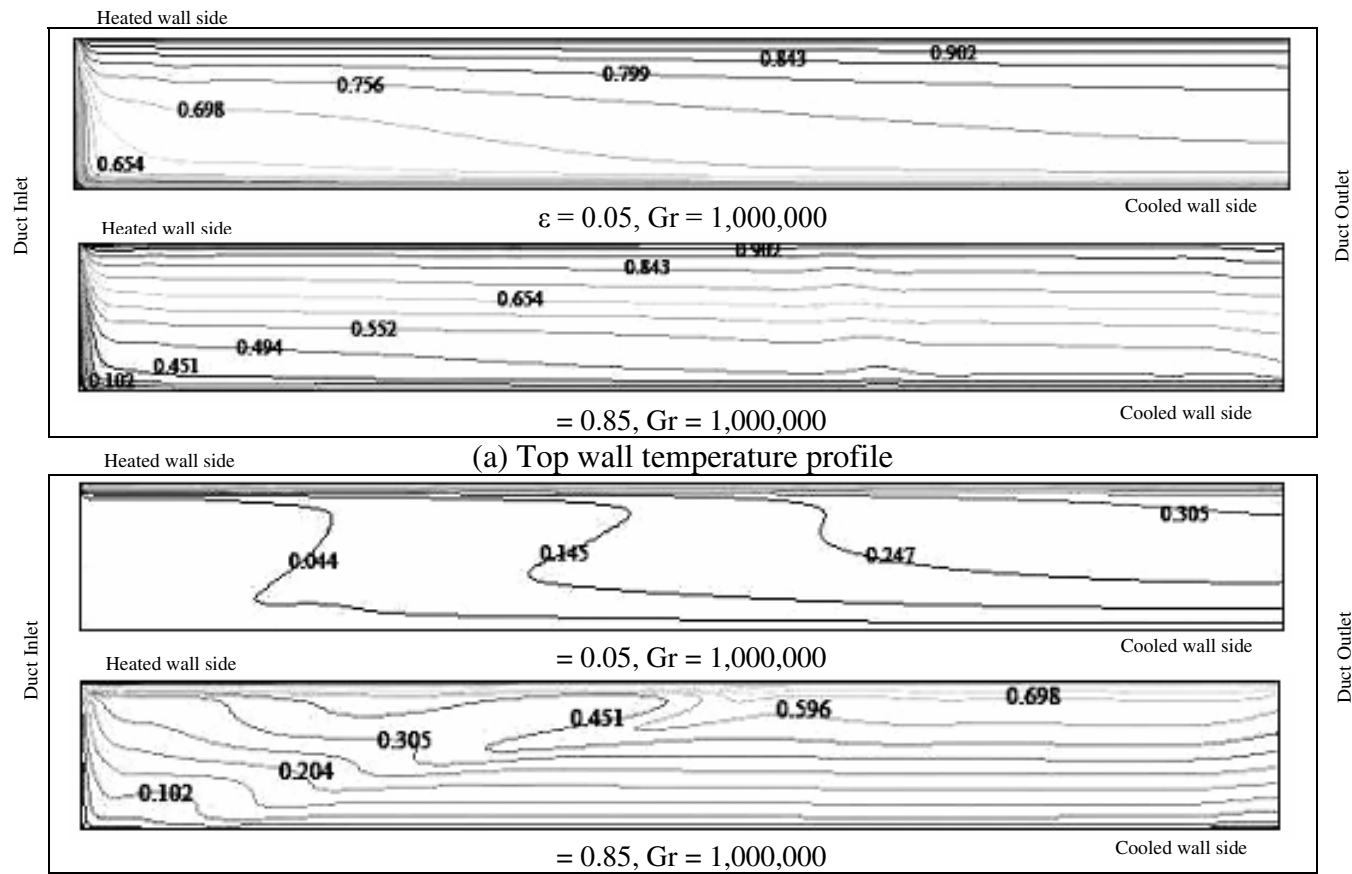

(b) Bottom wall temperature profile

Figure 5. Dimensionless temperature contours at the top and bottom duct walls along duct length

For $\varepsilon=0.05$, the temperature contours are highly localised near the heated (or cooled) side of the duct while for $\varepsilon=0.85$, the contours are more spread out over the wall surface. This indicates that the thermal radiation heat exchange among walls in fact acts to increase the average top wall temperature and decrease the bottom wall temperature. The impact of this temperature redistribution is seen from the comparison between Figures 3 and 6 .

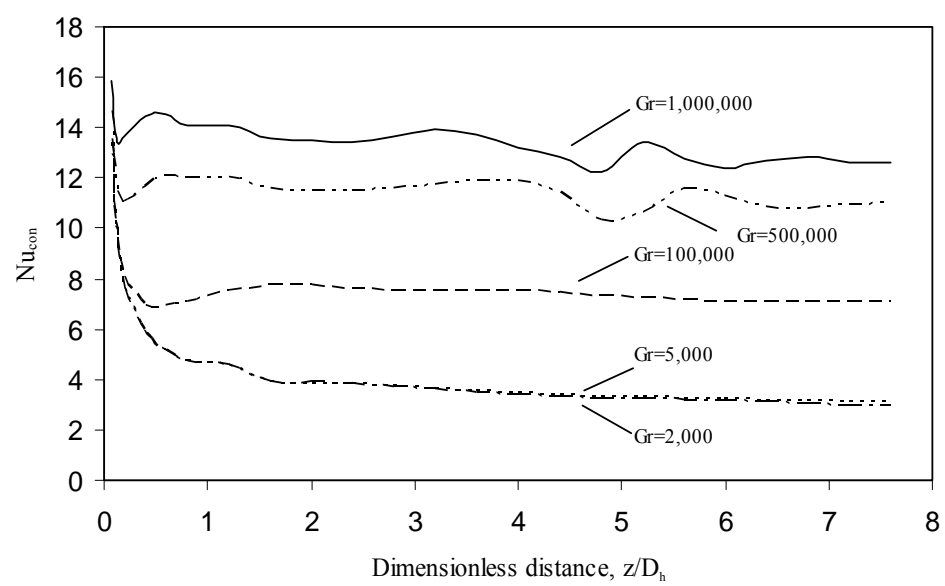

Figure 6 Variation of transverse average convective Nusselt number for $A R=1$ and $=0.85$ 
It is noted from Figure 6 that for high wall emissivity of 0.85 , the convective Nusselt number shows a wavy appearance when Gr exceeds 100,000. Such behaviour is not present for identical cases with low wall emissivity of 0.05 shown in Figure 3. The wall surface radiation effects are therefore deduced to be the cause of these $\mathrm{Nu}$ fluctuations, which are referred to as thermal instability of the flow. Incropera and Maughan[1,2] have observed similar behaviour for Nusselt number in bottomheated ducts without attributing that to radiation effects. The current work is the first reported instance of thermal instability in ducts arising from thermal radiation effects and sidewall heating.

The thermal instability essentially originates from the interaction between natural convection currents at the sidewalls and the thermal boundary layers at the adiabatic walls. As observed previously in relation to Figure 5, the adiabatic duct walls are heated or cooled by the thermal radiation exchange among duct walls. This leads to the development of thicker thermal boundary layers at these walls. In flows dominated by natural convection ( $\mathrm{Gr}>100,000)$, the convection currents at sidewalls are stronger and interact vigorously with thermal boundary layers at top and bottom walls. Unstable flow regimes are then created at the top and bottom walls along with variable heat transfer characteristics, which are recognised as thermal instability. An exact mechanistic explanation for thermal instability has yet to be developed.

In flows with weak natural convection $(\mathrm{Gr}<100,000)$, a poor interaction will occur between the convection currents at sidewalls and the thermal boundary layers at top and bottom walls. Therefore, the flow will not experience any significant fluid or thermal instability at the top and bottom walls due to thermal radiation effects.

Figure 7 considers the ratio of $\mathrm{Nu}_{\text {total }}$ for surface emissivities of 0.85 and 0.05 , which illustrates the thermal radiation effects on the total heat transfer. A value greater than one for this ratio indicates the degree of overall heat transfer enhancement arising from the duct wall thermal radiation. In Figure 7 , the ratio varies between 1.5 and 1.7 , and indicates significant heat transfer enhancement vindicating that the thermal radiation is indeed an important consideration in heated ducts even at low wall temperatures.

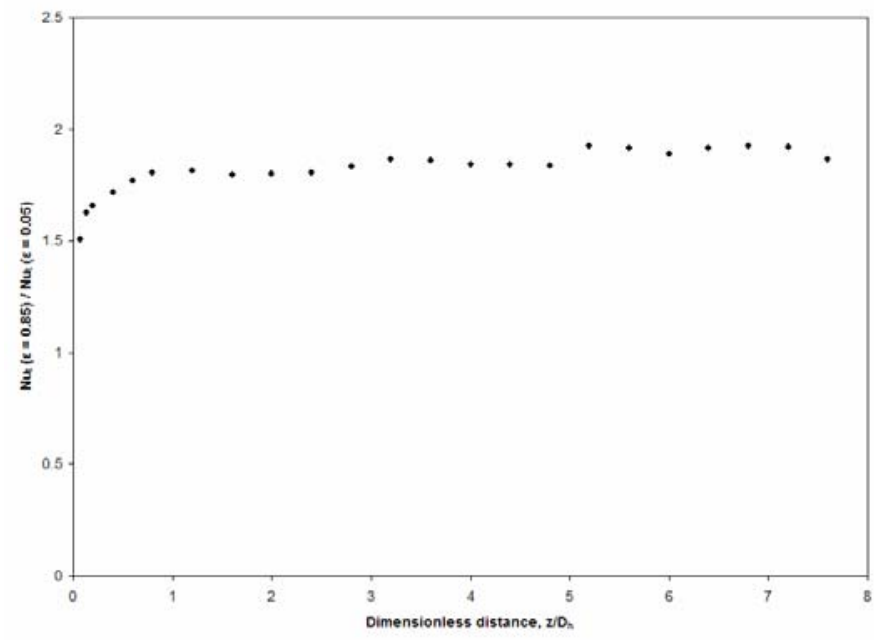

Figure 7. Variation of the total Nusselt number ratio at high $(\varepsilon=0.85)$ and low $(\varepsilon=0.05)$ emissivities for $\mathrm{Gr}=1000,000$

\section{Conclusions}

Considering the mechanisms of mixed convection and thermal radiation, a model has been successfully developed and used to examine the heat transfer characteristics of steady thermally developing laminar flow through a differentially heated horizontal rectangular duct. This novel investigation demonstrates the occurrence of thermal instability with duct sidewall heating and vindicates the significance of thermal radiation in heated ducts. The analysis clearly shows that mixed convection heat transfer rates are well above those achievable from forced convection-dominated 
flow. The surface radiation significantly alters the wall equilibrium temperature and generates thermal instability under certain conditions while enhancing the overall heat transfer rates. Even with low operating temperatures, the wall surface radiation in heated ducts makes a major contribution towards the total heat transfer rates.

\section{References}

[1] Maughan J. R. and Incropera F. P. 1987, Experiments on mixed convection heat transfer for airflow in a horizontal and inclined channel, International Journal of Heat and Mass Transfer, 30, pp. 1307-1318.

[2] Maughan J. R. and Incropera F. P. 1990, Regions of heat transfer enhancement for laminar mixed convection in a parallel plate channel, International Journal of Heat and Mass Transfer, 33, pp. 555-570.

[3] Nyce T. A., Ouazzani J.1992, Durand-Daubin A. and Rosenberger F., Mixed convection in a horizontal rectangular channel-experimental and numerical velocity distributions, International Journal of Heat and Mass Transfer, 35, pp. 1481-1494.

[4] Huang C. C. and Lin T. F.1994, Buoyancy induced flow transition in mixed convective flow of air through a bottom heated horizontal rectangular duct, International Journal of Heat and Mass Transfer, 37, pp. 1235-1255.

[5] Sillekens J. J. M., Rindt C. C. M. and Van Steenhoven A. A. 1998, Development of laminar mixed convection in a horizontal square channel with heated sidewalls, International Journal of Heat and Fluid Flow, 19, pp. 270-281.

[6] Gau C., Jeng Y. C. and Liu C. G. 2000, An experimental study on mixed convection in a horizontal rectangular channel heated from a side, Transactions of the ASME. Journal of Heat Transfer, 122, pp. 701-7.

[7] Corcione M. 2003, Effects of the thermal boundary conditions at the sidewalls upon natural convection in rectangular enclosures heated from below and cooled from above, International Journal of Thermal Sciences, 42, pp. 199-208.

[8] Yang G. and Ebadian M. A. 1992, Analysis of heat transfer in arbitrary shaped ducts: Interaction of forced convection and radiation, International Communications in Heat and Mass Transfer, 19, pp. 103-115.

[9] Colomer G., Costa M., Consul R. and Oliva A. 2004, Three-dimensional numerical simulation of convection and radiation in a differentially heated cavity using the discrete ordinates method, International Journal of Heat and Mass Transfer, 47, pp. 257-269.

[10] Incropera F.P. and DeWitt D. P. 2002, Introduction to Heat Transfer, Fourth Edition, John Wiley \& Sons Inc., New York, pp. 831.

[11] Özisik M. N. 1973, Radiative Transfer, John Wiley \& Sons Inc., New York

[12] Patankar S.V. 1980, Numerical Heat Transfer and Fluid Flow, Hemisphere, Washington, DC

[13] GAMBIT 2.2 2004 User's Guide, Lebanon, NH, Fluent Inc.

[14] FLUENT 6.1 2003 User's Guide, Lebanon, NH, Fluent Inc.

[15] Ramesh, N., and Venkateshan, S.P. 2001, Experimental Study of Natural Convection in a Square Enclosure using Differential Interferometer, Int. Journal of Heat and Mass Transfer, 44, No. 6, pp. $1107-1117$

[16] Ramesh, N., and Merzkirch, W. 2001, Combined Convective and Radiative Heat Transfer in Side-Vented Open Cavities, Int. J. Heat Fluid Flow, 22, No. 2, pp. 180 - 187.

[17] Ramesh, N., Balaji, C., and Venkateshan, S.P. 2001, An Experimental Study of Natural Convection and Surface Radiation in an Open Cavity, Int. J. Heat and Technology, 19, No. 2, pp. $89-94$.

[18] Narayanaswamy R, King A J C and Chandratilleke T T 2007, Multimode heat transfer in an enclosure with multiple partitions, Aust. J. of Mech Eng., 4, No. 1. 